\title{
Titan Submarine: Exploring The Depths of Kraken Mare
}

\author{
Steven R. Oleson ${ }^{1}$ \\ NASA Glenn Research Center, Cleveland, Ohio 44135
}

Ralph D. Lorenz ${ }^{2}$

Johns Hopkins University, Applied Physics Laboratory, Laurel, Maryland 20723

Michael V. Paul ${ }^{3}$

The Pennsylvania State University, Applied Research Laboratory, State College, Pennsylvania 16804

The conceptual design of a submarine for Saturn's moon Titan was a funded NASA's Innovative Advanced Concepts (NIAC) Phase I for 2014. The effort investigated what science a submarine for Titan's liquid hydrocarbon $\sim 93 \mathrm{~K}\left(-180^{\circ} \mathrm{C}\right)$ seas might accomplish and what that submarine might look like. Focusing on a flagship class science system $(\sim 100 \mathrm{~kg})$ it was found that a submersible platform can accomplish extensive and exciting science both above and below the surface of the Kraken Mare The submerged science includes mapping using side looking sonar, imaging and spectroscopy of the sea at all depths, as well as sampling of the sea's bottom and shallow shoreline. While surfaced the submarine will not only sense weather conditions (including the interaction between the liquid and atmosphere) but also image the shoreline, as much as $2 \mathrm{~km}$ inland. This imaging requirement pushed the landing date to Titan's next summer period ( 2047) to allow for continuous lighted conditions, as well as direct-to-Earth (DTE) communication, avoiding the need for a separate relay orbiter spacecraft. Submerged and surfaced investigation are key to understanding both the hydrological cycle of Titan as well as gather hints to how life may have begun on Earth using liquid/sediment/chemical interactions. An estimated $25 \mathrm{Mb}$ of data per day would be generated by the various science packages. Most of the science packages (electronics at least) can be safely kept inside the submarine pressure vessel and warmed by the isotope power system. This paper discusses the results of Phase I as well as the plans for Phase II.

$\begin{array}{ll} & \\ \text { APL } & =\text { Applied Physics Laboratory } \\ \text { ARL } & =\text { Applied Research Laboratory } \\ \text { BSA } & =\text { Benthic Sample Acquisition } \\ \text { CAP } & =\text { Chemistry Analysis Package } \\ \text { CCD } & =\text { charged-couple device } \\ \text { COMPASS } & =\text { COllaborative Modeling and Parametric Assessment of Space Systems } \\ \text { DOR } & =\text { Differential One-way Ranging } \\ \text { DS } & =\text { Depth Sounder } \\ \text { DTE } & =\text { direct to Earth } \\ \text { GCMS } & =\text { Gas Chromatograph Mass Spectrometer } \\ \text { GRC } & =\text { NASA Glenn Research Center } \\ \text { IRS } & =\text { Infrared Spectrometer } \\ \text { JHU } & =\text { Johns Hopkins University } \\ \text { MEL } & =\text { Master Equipment List } \\ \text { MET } & =\text { Meteorology Package } \\ \text { MS-MS } & =\text { tandem mass spectrometry }\end{array}$

${ }^{1}$ COMPASS Lead, Mission Analysis and Architectures Branch, 21000 Brookpark Road, and AIAA Senior Member.

${ }^{2}$ Principal Professional Staff, Space Department, Johns Hopkins University Applied Physics Laboratory

${ }^{3}$ Space Systems Engineer, The Pennsylvania State University, Applied Research Laboratory 


$\begin{array}{ll}\text { NAV } & =\text { Navigation Systems } \\ \text { NIAC } & =\text { NASA's Innovative Advanced Concepts } \\ \text { P3 } & =\text { Physical Properties Package } \\ \text { PEL } & =\text { Power Equipment List } \\ \text { PSU } & =\text { Pennsylvania State University } \\ \text { SI } & =\text { Surfaced Imager } \\ \text { SIP } & =\text { Standard Interface Plane } \\ \text { SS } & =\text { Sidescan Sonar } \\ \text { SSP } & =\text { Surface Science Package } \\ \text { TBD } & =\text { to be determined } \\ \text { TiME } & =\text { Titan Mare Explorer } \\ \text { TSSM } & =\text { Titan Saturn System Mission } \\ \text { UI } & =\text { Undersea Imager } \\ \text { WBS } & =\text { work breakdown structure }\end{array}$

\section{Introduction}

Each year the NIAC program asks researchers to propose ideas for space technology or missions that could provide significant scientific advances in the next few decades. In June 2014, NIAC announced 12 winners from the latest proposal activity to be funded for a 9 month study effort. A team of three investigators, Steve Oleson (NASA Glenn Research Center (GRC)), Ralph Lorenz (Johns Hopkins University (JHU) Applied Physics Laboratory (APL)), and Michael Paul (Pennsylvania State University (PSU) Applied Research Laboratory (ARL)), proposed developing a conceptual design for an autonomous submersible to explore the liquid hydrocarbon seas of Saturn's Moon, Titan, with the support of GRC's COllaborative Modeling and Parametric Assessment of Space Systems (COMPASS) concurrent engineering team. By addressing the challenges of autonomous submersible exploration in a cold outer solar system environment, a Titan Sub could serve as a pathfinder for even more exotic future exploration of the subsurface water oceans moons like Europa. This paper serves to briefly introduce the challenges and conceptual design of the Phase I effort. A complete design report with details can be found elsewhere. ${ }^{1}$ Specific challenges for subsystems such as thermal, science, and ballast systems can be found in other publications. ${ }^{2,3,4}$ The paper concludes with plans for Phase II which was awarded in July 2015.

\section{Titan Overview}

Titan is the largest moon of Saturn. It is the only natural satellite known to have a dense atmosphere and the only object other than Earth for which clear evidence of stable bodies of surface liquid has been found. The atmosphere of Titan is largely nitrogen with clouds of methane and ethane. The climate-including wind and rain - creates surface features similar to those of Earth, such as dunes, rivers, lakes, seas and deltas, and is dominated by seasonal weather patterns as on Earth.

1. Previous Studies

The unique exploration opportunities afforded by Titan's dense atmosphere, low gravity environment and its seas have stimulated many mission concepts over the years. ${ }^{5}$ These have included landers, airships, hot air balloons, airplanes, helicopters and even hovercraft.

Attention was drawn to exploration of liquid environments on Titan after the discovery of seas in the North Polar Region by Cassini's radar instrument in 2006 (the northern region was then in winter darkness) and the later mapping of these seas (Figure 1). These seas were named by the International Astronomical Union Committee on Planetary Nomenclature after mythical sea monsters. They are, in order of ascending size, Punga Mare, Ligeia Mare, and Kraken Mare and became more or less fully-mapped in 2013.

The joint NASA-ESA 2008-2009 Flagship mission study Titan Saturn System Mission (TSSM) featured a Titan orbiter, a radioisotope-powered Montgolfiere (hot air balloon) and a lake lander. The lake lander was essentially a small version of the Huygens probe, with a 9-hr lifetime limited by its primary battery.

Another concept for a Titan boat was proposed to the NASA Discovery solicitation in 2010. Of the $\sim 29$ proposals submitted, Titan Mare Explorer (TiME) was one of three selected for a Phase A study in 2011. That study resulted in very detailed examination of key practical aspects of exploring Titan's hydrocarbon seas, including entry/descent dispersions, splashdown mechanics, wave height probabilities, tidal circulation, ocean thermodynamics and sonar operations. TiME ${ }^{6}$ would have launched in 2016, with arrival at Ligeia Mare in July 2023. Unfortunately, delays in the development of the Stirling Radioisotope Generators made selection of the mission for implementation on this schedule impossible. The subsequent Discovery solicitation in 2014 precluded any radioisotope power at all, due to fuel encapsulation schedule challenges. 


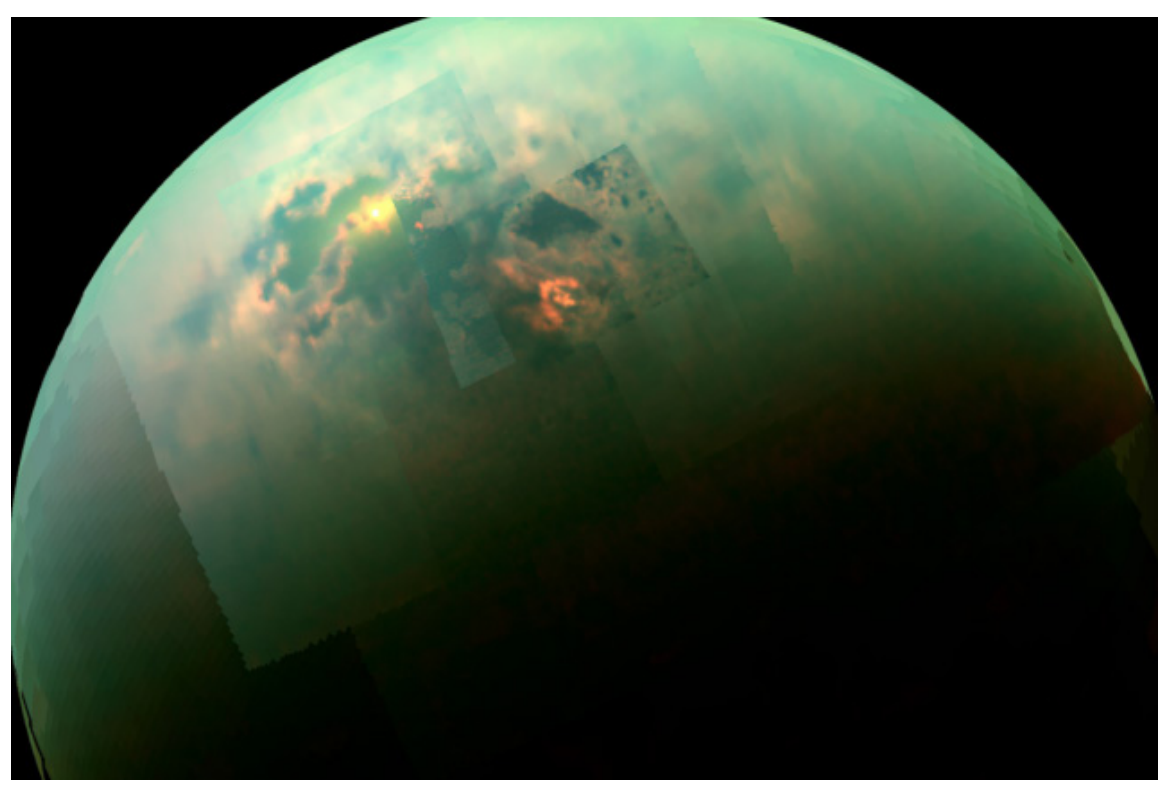

Figure 1. Cassini captures sunlight glinting off of Titan's seas.

The arrival date at Titan is critical for an affordable stand-alone mission to Titan's seas, in that direct-to-Earth communication from Titan's seas at high northern latitudes $\left(>65^{\circ} \mathrm{N}\right.$ latitude) can only be performed when the Earth and the Sun are sufficiently high in the Titan sky. Northern summer solstice occurs in 2017; the equinox is in 2024. After around 2026, Earth is too far south, and thus is too low in the sky or is invisible altogether as seen from Titan's seas.

\section{Science Requirements and Instrumentation}

\section{Science Overview}

The scientific goals of the Titan Submarine derive from those developed for the 2007 Titan Explorer Flagship study ${ }^{7}$ and are shown in Table 1. Although the seas on Titan were discovered only during that study, the objectives were broad enough to remain community-endorsed in subsequent studies such as TSSM and the Decadal Survey.

Table 1. The Scientific Goals of the 2007 Titan Explorer Flagship Study

\begin{tabular}{|l|l|}
\hline \multicolumn{2}{|c|}{ Exploring an Earthlike Organic-Rich World } \\
\hline $\begin{array}{l}\text { Objective 1: Titan: An Evolving Earthlike System } \\
\text { - How does Titan function as a system? How do we explain the } \\
\text { similarities and differences among Titan, Earth, and other solar } \\
\text { system bodies? To what extent are these controlled by the }\end{array}$ & $\begin{array}{l}\text { Objective 2: Titan's Organic Inventory: A Path to Prebiological } \\
\text { Molecules }\end{array}$ \\
$\begin{array}{l}\text { conditions of Titan's formation and to what extent by the } \\
\text { complex interplay of ongoing processes of geodynamics, } \\
\text { geology, hydrology, meteorology, and aeronomy in the Titan } \\
\text { organic chemistry in the atmosphere, within its lakes, on its } \\
\text { system? }\end{array}$ & $\begin{array}{l}\text { surface, and in its subsurface water ocean? How far has this } \\
\text { chemical evolution progressed over time? How does this inventory } \\
\text { differ from known abiotic organic material in meteorites and } \\
\text { biological material on Earth? }\end{array}$ \\
\hline
\end{tabular}

\section{Science Requirements}

More specifically, the scientific goals of the Titan Submarine shown in Table 2 are the same as those of the Decadal Survey lake lander, but modified to embrace the growing interest in the diverse shorelines of Titan's seas which can be explored by a mobile sea platform, and to recognize the paleoclimate study potential in the seabed sediments.

\section{Instruments}

The science requirements drove the strawman payload listed in the Table 3. The chemical composition of the seas (and any sediments) is a complex topic, as evidenced in the discussion of solid composition analysis in Ref. 7. We have not specified the internal makeup of the Chemical Analysis Package (CAP). It might comprise a sample volatilization system coupled to a Gas Chromatograph Mass Spectrometer (GCMS), tandem mass spectrometry (MS-MS) or similar analyzer for broad chemical characterization and isotopic measurement. Additional possibilities 
include Raman, fluorescent or other techniques for specific species of astrobiological interest. The overall resource envelope is patterned after the Sample Analysis at Mars package on Mars Science Laboratory Curiosity.

Table 2. Scientific Goals of the Titan Submarine

\begin{tabular}{|l|l|l|l|}
\hline & \multicolumn{1}{|c|}{ Objective } & \multicolumn{1}{|c|}{ Heritage } & \multicolumn{1}{|c|}{ Contributing Instruments } \\
\hline A1 & $\begin{array}{l}\text { Explore the morphology and character of the seabed to } \\
\text { understand the history of the basin and sediment deposits }\end{array}$ & New & $\begin{array}{l}\text { Depth Sounder (DS), Sidescan Sonar (SS), } \\
\text { Undersea Imager (UI) }\end{array}$ \\
\hline A2 & $\begin{array}{l}\text { Explore the morphology of shoreline features to understand } \\
\text { Titan's geological history }\end{array}$ & TE 2007/TSSM/TiME & Surface Imager (SI) \\
\hline A3 & $\begin{array}{l}\text { Measure sea-surface meteorology to constrain larger-scale } \\
\text { weather activity and air-sea exchange }\end{array}$ & TSSM/Decadal/TiME & Meteorology Package (MET), Navigation (NAV) \\
\hline A4 & $\begin{array}{l}\text { Measure sea physical characteristics (currents, waves, } \\
\text { turbidity) and their variations over space and time }\end{array}$ & TSSM/Decadal/TiME & $\begin{array}{l}\text { Physical Properties Package (P3), SI, Navigation, } \\
\text { (UI, DS) }\end{array}$ \\
\hline A5 & $\begin{array}{l}\text { Measure horizontal and depth variations of major constituents } \\
\text { to constrain exchange and mixing processes }\end{array}$ & Decadal (option) & Infrared Spectrometer (IRS), P3, CAP, (DS) \\
\hline B1 & $\begin{array}{l}\text { Measure trace organics in sea, with emphasis on prebiotic } \\
\text { chemistry }\end{array}$ & TSSM/Decadal/TiME & CAP, IRS \\
\hline B2 & $\begin{array}{l}\text { Measure isotopic ratios of noble gases and organics to } \\
\text { constrain origin and evolution of Titan }\end{array}$ & TSSM/Decadal/TiME & CAP \\
\hline B3 & Measure composition of seabed material (best effort) & Decadal/New & Benthic Sample Acquisition (BSA), CAP \\
\hline
\end{tabular}

Table 3. Science Instruments for the Titan Submarine

\begin{tabular}{|c|c|c|c|c|c|}
\hline & Instrument & Technique & Rationale & Requirements & Basis \\
\hline \multirow{5}{*}{$\frac{\grave{\partial}}{I}$} & CAP & $\begin{array}{l}\text { Liquid sample acquisition system } \\
\text { coupled to multiple analytic } \\
\text { instruments (nominally GCMS) }\end{array}$ & $\begin{array}{l}\text { Measure bulk and trace } \\
\text { constituents of sea at different } \\
\text { locations and depths }\end{array}$ & $\begin{array}{l}\text { Inlet isolated from heat } \\
\text { source; } 40 \mathrm{~kg}, 80 \mathrm{~W} \text { when } \\
\text { sampling }(2 \mathrm{hr} \text {; once per } \\
2 \mathrm{~d})\end{array}$ & $\begin{array}{l}\text { Curiosity/Sample Analysis } \\
\text { at Mars }\end{array}$ \\
\hline & SI & $\begin{array}{l}\text { Panoramic charged-couple device } \\
\text { (CCD) imager (gimballed) on } \\
\text { upper structure }\end{array}$ & $\begin{array}{l}\text { Observe sea surface, shoreline } \\
\text { geomorphology, clouds, } \\
\text { atmospheric optics }\end{array}$ & $\begin{array}{l}\text { Topside mount, } 1 \mathrm{~m} \text { above } \\
\text { sea surface; } 4 \mathrm{~kg} \text { including } \\
\text { housing; } 10 \mathrm{~W} \text { when } \\
\text { imaging }(2 \mathrm{hr} / \mathrm{d})\end{array}$ & $\begin{array}{l}\text { Mars Exploration Rover } \\
\text { Pancam }\end{array}$ \\
\hline & $\overline{D S}$ & $\begin{array}{l}\text { Single down-looking acoustic } \\
\text { sounder }\end{array}$ & $\begin{array}{l}\text { Low frequency }(10 \text { to } 20 \mathrm{kHz}) \text { to } \\
\text { measure depth to bottom, } \\
\text { possibly detect layers, bubbles, } \\
\text { etc. }\end{array}$ & $\begin{array}{l}\text { Nadir view; } 0.5 \mathrm{~kg} 2 \mathrm{~W} \\
\text { continuous }\end{array}$ & $\begin{array}{l}\text { TiME MP3, commercial } \\
\text { fish finders }\end{array}$ \\
\hline & MET & $\begin{array}{l}\text { Pressure, temperature, wind speed } \\
\text { and direction, methane humidity } \\
\text { on surface }\end{array}$ & $\begin{array}{l}\text { Record meteorological } \\
\text { variability, forcing of air/sea } \\
\text { exchange }\end{array}$ & $\begin{array}{l}\text { Topside mount, } 1 \mathrm{~m} \text { above } \\
\text { sea surface, desirably away } \\
\text { from heat source; } 3 \mathrm{~kg} 6 \mathrm{~W} \\
\text { continuous }\end{array}$ & $\begin{array}{l}\text { TiME MP3, Pathfinder } \\
\text { ASI/MET, terrestrial field } \\
\text { instruments }\end{array}$ \\
\hline & $\overline{\mathrm{P} 3}$ & $\begin{array}{l}\text { Sea temperature, speed of sound, } \\
\text { dielectric constant and turbidity }\end{array}$ & $\begin{array}{l}\text { Structure of liquid column } \\
\text { (stratification), suspended } \\
\text { sediment, air/sea exchange, local } \\
\text { variations in bulk ethane/methane }\end{array}$ & $\begin{array}{l}\text { Isolated from heat source; } \\
2 \mathrm{~kg} ; 6 \mathrm{~W} \text { continuous }\end{array}$ & \begin{tabular}{|l} 
TiME MP3/Huygens \\
Surface Science Package \\
(SSP)
\end{tabular} \\
\hline \multirow{4}{*}{ 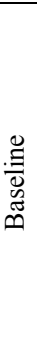 } & SS & $\begin{array}{l}\text { Side-looking acoustic imaging } \\
\text { array }\end{array}$ & $\begin{array}{l}\text { Acoustic imaging of seabed } \\
\text { morphology }\end{array}$ & $\begin{array}{l}\text { Bottom/side view; } 10 \mathrm{~W} \\
\text { when operating; } 8 \mathrm{hr} / \mathrm{d}\end{array}$ & $\begin{array}{l}\text { Terrestrial unmanned } \\
\text { underwater vehicle }\end{array}$ \\
\hline & UI & $\begin{array}{l}\text { Medium-field CCD imager } \\
\text { equipped with multicolor } \\
\text { illuminators }\end{array}$ & $\begin{array}{l}\text { Optical imaging of seabed } \\
\text { (combine with SI if vehicle } \\
\text { orientation permits) }\end{array}$ & $\begin{array}{l}\text { Forward view; } 3 \mathrm{~kg} \\
\text { including housing; } 20 \mathrm{~W} \\
\text { when imaging; } 1 \mathrm{hr} / \mathrm{d}\end{array}$ & $\begin{array}{l}\text { Curiosity Mars Hand Lens } \\
\text { Imager }\end{array}$ \\
\hline & BSA & $\begin{array}{l}\text { Grinding/suction system to ingest } \\
\text { solid or semi-solid seabed } \\
\text { materials }\end{array}$ & $\begin{array}{l}\text { Deliver seabed sediments to CAP } \\
\text { instrument }\end{array}$ & $\begin{array}{l}\text { Forward/lower view; } 5 \mathrm{~kg} \text {; } \\
50 \mathrm{~W} \text { when operating } 1 \mathrm{hr} / \\
2 \mathrm{~d}\end{array}$ & $\begin{array}{l}\text { Phoenix rasp plus suction } \\
\text { pump }\end{array}$ \\
\hline & IRS & & & $8 \mathrm{~kg} ; 20 \mathrm{~W} ; 2 \mathrm{hr} / \mathrm{d}$ & $\begin{array}{l}\text { Miniature Thermal } \\
\text { Emission Spectrometer, } \\
\text { laboratory instruments }\end{array}$ \\
\hline 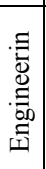 & NAV & $\begin{array}{l}\text { Pressure depth gauge, inertial } \\
\text { measurement unit, plus } \\
\text { Doppler/Delta Differential One- } \\
\text { way Ranging (DOR) radio } \\
\text { measurements }\end{array}$ & Infer ocean currents & $\begin{array}{l}\text { Bookkept under Guidance, } \\
\text { Navigation, and Control } \\
\text { System }\end{array}$ & Various \\
\hline
\end{tabular}




\section{Concept of Operations}

The baseline 90 day mission would be to sail alternately submerged and surfaced around and through Kraken Mare investigating the shoreline and inlets to evaluate the sedimentary interaction both on the surface and below. Depths of Kraken have yet to be sensed (Ligeia to the north is thought to be $200 \mathrm{~m}$ (656 ft) deep), but a maximum depth of $1,000 \mathrm{~m}(3.281 \mathrm{ft}$ ) for Kraken Mare was assumed for the design (Figure 2). The sub would spend 20 days at the interface between Kraken Mare and Ligeia Mare for clues to the drainage of liquid methane into the currently predicted predominantly ethane Kraken Mare. During an extended 90 day mission it would transit the throat of Kraken (now 'Seldon Fretum') and perform similar explorations in other areas of Kraken Mare. Once this half year of exploration is completed the submarine could be tasked to revisit points of interest and perhaps do a complete sonar mapping of the seas. All in all, the submarine could explore over $3,000 \mathrm{~km}(1,864 \mathrm{mi})$ in its primary mission at an average speed of $0.3 \mathrm{~m} / \mathrm{s}$. The Concept of Operations from launch are shown in Figure 3. Launch, cruise and delivery are notional and will be better defined in phase II.

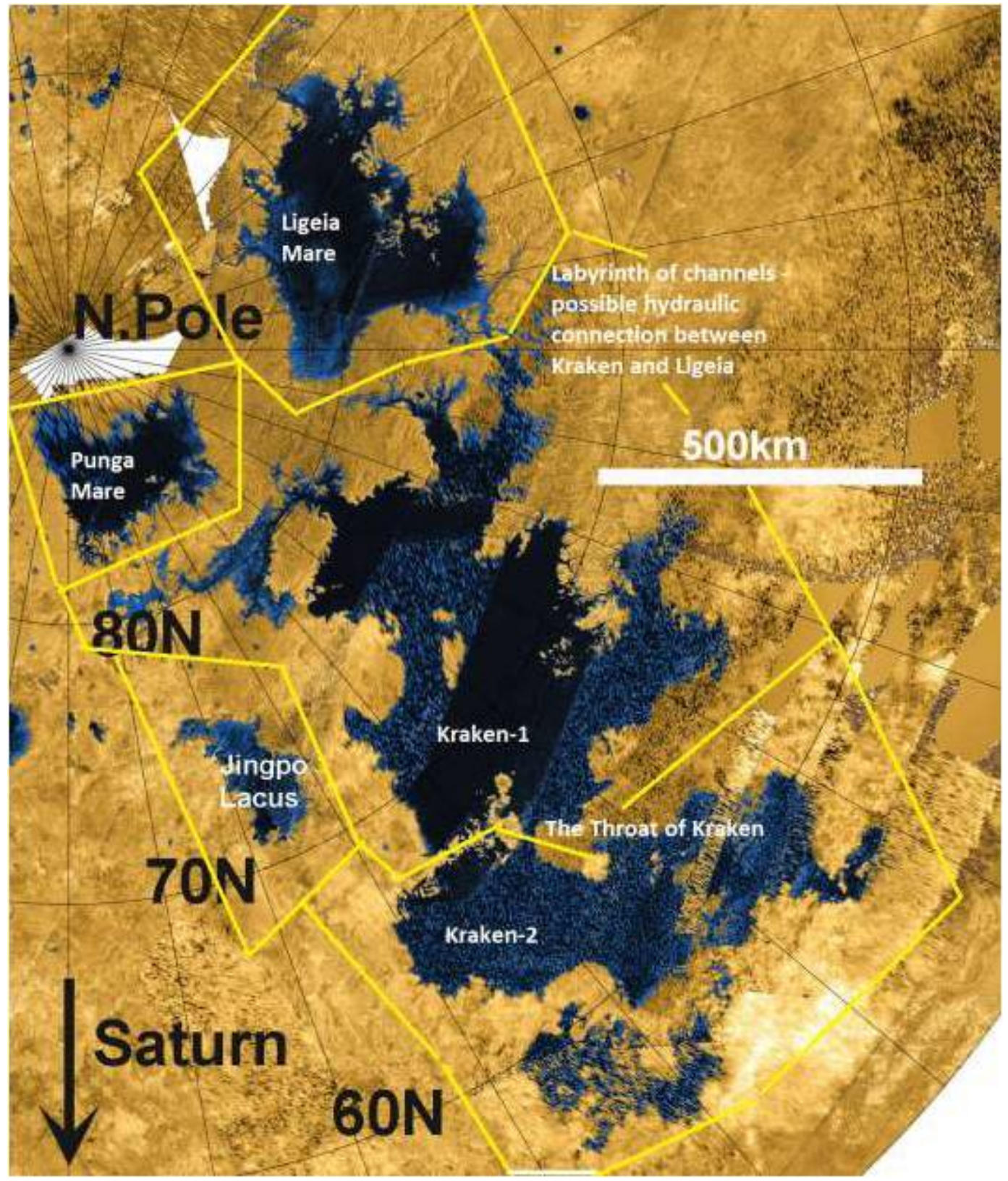

Figure 2. Titan's Seas or Mare in the Northern Hemisphere. 


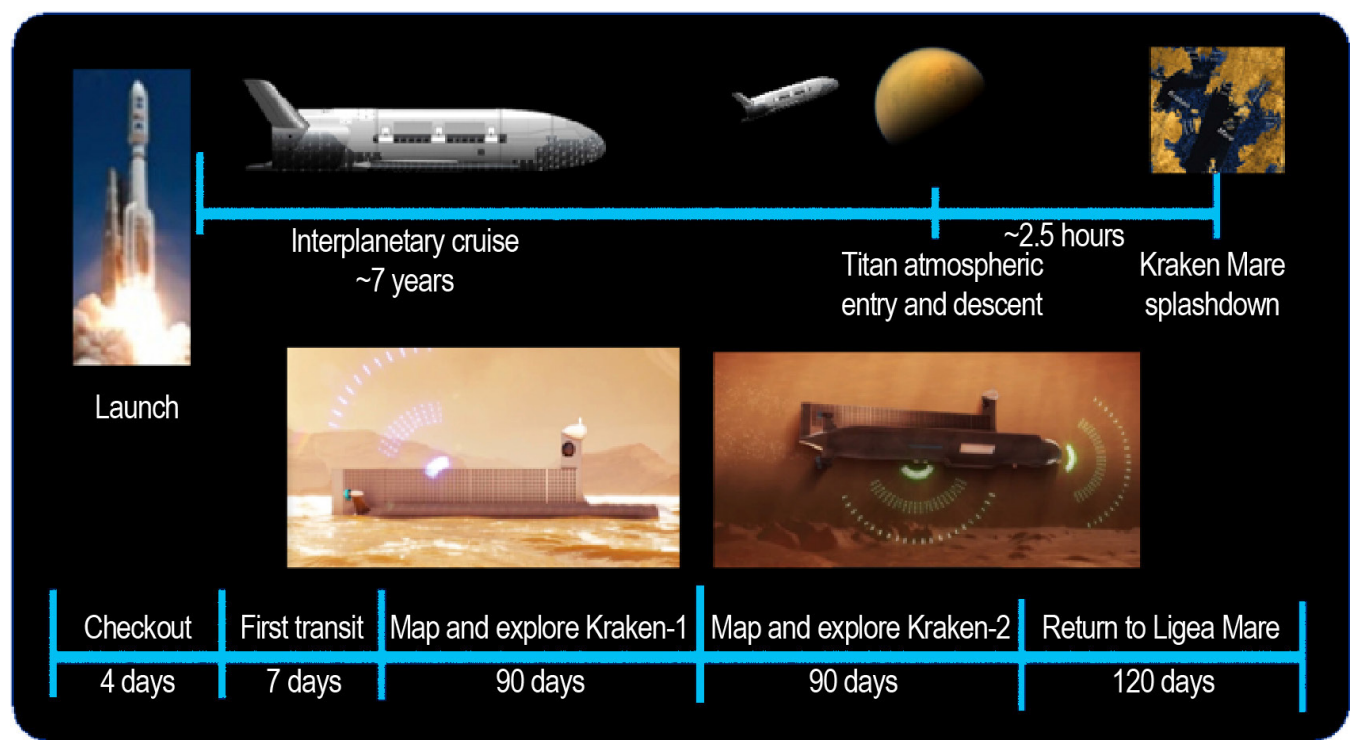

Figure 3. Concept of Operations.

\section{Submarine Shape Trades and Delivery Options}

A preliminary trade matrix was developed to explore the possible shapes of the submarine based on terrestrial experience, science needs and the added challenges of launching and encapsulating the submarine in an aeroshell. Table 4 shows the top level advantages and disadvantages of current terrestrial designs for the Titan Sub mission requirements. While sea gliders have shown to be able to transit great distances with very little power (sinking and gliding with wings and then resurfacing using a ballast system) a science requirement for hovering and in-situ sampling would be difficult for such a vehicle. Due to the size of the seas (1000's of kilometers) the Titan Sub would need to be an efficient cruiser which excludes the remotely operated vehicle and diving saucer options. Unfortunately, the length of the torpedo shaped submarine (sized due to required specific weight - it needs to float and sink along with its required power and science instrument mass) would be too large for state of the art $4.5 \mathrm{~m}$ aeroshells. While larger button shaped aeroshells can be built they would be too large for the $5 \mathrm{~m}$ launch vehicle fairing. This last challenge required new options for the aerodescent system.

Table 4. Advantages and Disadvantages of Current Terrestrial Designs

\begin{tabular}{|c|c|c|c|c|}
\hline $\begin{array}{c}\text { Driving requirement or } \\
\text { attribute }\end{array}$ & $\begin{array}{c}\text { Remotely operated } \\
\text { vehicle }\end{array}$ & Diving saucer & $\begin{array}{c}\text { Torpedo shaped } \\
\text { unmanned underwater } \\
\text { vehicle }\end{array}$ & $\frac{1}{12}$ \\
\hline $\begin{array}{l}\text { Science submerged and } \\
\text { surfaced, hovering for in-situ } \\
\text { sampling }\end{array}$ & Yes & Yes & Yes & No \\
\hline $\begin{array}{l}\text { Distance to travel/time: } \\
2000 \mathrm{~km} / 90 \text { days } \sim 0.5 \mathrm{~m} / \mathrm{s} \\
\text { Aspect ratio }>4: 1 \text { reduces } \\
\text { power } 4 \text { times, smooth exterior }\end{array}$ & NO & No & Yes & Yes \\
\hline $\begin{array}{l}\text { SOA aeroshell limit: } \\
<4.5 \mathrm{~m}, 0.6 \text { specific weight }\end{array}$ & Yes & Yes & No & No \\
\hline $\begin{array}{l}\text { Communications: DTE needs } \\
\text { large antenna area to reduce } \\
\text { power, Earth nearer horizon } \\
\text { than zenith }\end{array}$ & & $\begin{array}{l}\text { Yes } \\
\text { Dish integrated } \\
\text { into saucer? }\end{array}$ & $\begin{array}{l}\text { Yes } \\
\text { Phased array } \\
\text { on body? }\end{array}$ & $\begin{array}{c}\text { Yes } \\
\text { Phased array } \\
\text { on body? }\end{array}$ \\
\hline
\end{tabular}




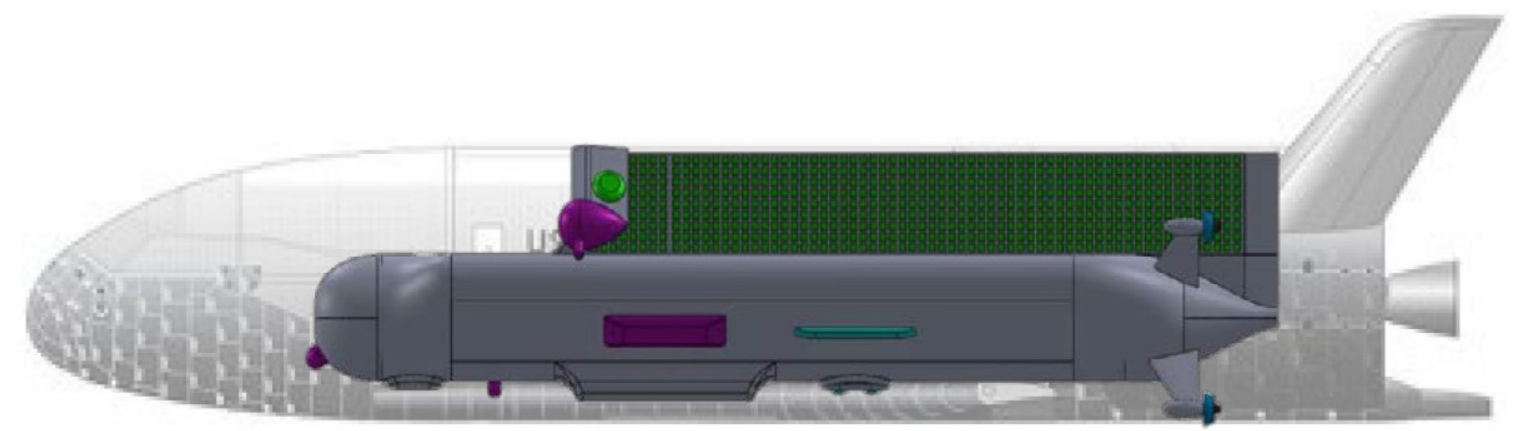

Figure 4. Titan Submarine in Notional X-37 derived lifting body. Acknowledgment: X-37B outline courtesy of Giuseppe De Chiara (used with permission).

The downselected torpedo shape of the vehicle needs a new entry/descent approach. While inflatable aeroshells might also work, a lifting body (based on the proven X-37B design) was chosen to hold the submarine through launch and support it through cruise with thermal, communications, propulsion, and navigation (Figure 4). The lifting body would then slow the submarine through Titan aeroentry, glide to the proper touchdown point, and perform a soft landing on the surface of Kraken Mare. The Space Shuttle Orbiter was assessed for emergency water landing capability in the 1970s. The Titan Sub's aerovehicle would touch down on Kraken Mare in a similar manner. At some point in the landing sequence, the backshell would be separated from the aerovehicle, the submarine separated and the lifting body allowed to sink. This descent and delivery concept (along with other alternatives) will be explored in detail as part of a Phase II study.

\section{Submarine Design Details}

The submarine design faced a great many challenges; some less difficult, some much more difficult than a terrestrial sub. Pressures at depth in a liquid ethane ( $\sim 60$ percent the density of water) sea on the smaller world of Titan ( 1/5 Earth's gravity) meant that even at the maximum design depth of $1,000 \mathrm{~m}(3,281 \mathrm{ft})$ the pressure to be endured was $1 / 10^{\text {th }}$ of that a terrestrial sub would encounter. The sub would need to endure only $\sim 10$ bar of pressure at maximum depth on titan, not the 100 bar $(10 \mathrm{MPa})$ pressure it would have to endure in Earth's oceans. This, however also meant that it needed to have a lower average density in order to be positively and neutrally buoyant to operate at the surface and below. Another challenge was that the extremely low temperature $\left(-180^{\circ} \mathrm{C}\right)\left(-292^{\circ} \mathrm{F}\right)$ of the liquid ethane would quickly cool down most terrestrial submarines. The use of isotope power systems (two $\sim 500 \mathrm{~W}$ Stirling Radioisotope Generators) meant that the submarine had plenty of power and waste heat to keep the internal components at room temperature, with the installation of insulation on the inside of the hull. These isotope systems could not only power the sub for several years beneath the waves of Kraken Mare, but also power the sub and the lifting body during the cruise from Earth to Titan. The power challenges and the thermal requirements led to the use of radioisotope generators. A fission reactor system, while heavier, may also be a feasible power system. An ethane fuel cell, using oxidizers brought from Earth would limit the vehicle to less than a week of operation to say nothing of how the combined vehicles would be powered on the way to Titan.

Communications proved to be a great challenge, but one also solved by use of the isotope power system. While methane has been shown to be radio frequency transparent, the presumably more-ethane rich composition of Kraken has not yet been shown to be transparent (a topic of ongoing Cassini investigation). As such the submarine, like its terrestrial counterpart will need to surface to communicate. Choice of a 2047 landing date not only ensures continuous lighting conditions for surface imaging, but also allows for direct communications with the Earth. From the Kraken Mare, Earth is never more than $6^{\circ}$ from the Sun. As such, it was decided to not use an orbiter (which would have needed an isotope power system for itself) and to double the isotope power system of the submarine to permit communications DTE while the sub is on the surface and then provide extra power for propulsion and science when submerged. Despite the power available, the DTE antenna would need to be large to span the approximately 1.2 billion $\mathrm{km}$ (746 million $\mathrm{mi}$ ) to Earth. Even using geostationary satellites terrestrial submarines only need to communicate distances of $36,000 \mathrm{~km}(22,370 \mathrm{mi})$ when surfaced. 
The concept shown in Figure 5 features a 'sail' or 'dorsal fin' above the hull which is a 4- by $0.5-\mathrm{m}$ (13.1- by 1.6-ft) fixed phased array antenna. (Overall sub dimensions are shown in Figure 7.) This antenna can provide greater than 500 bps for two $8 \mathrm{hr}$ Deep Space Network communications passes per day. It must operate in a $1.5 \times 10^{5} \mathrm{~Pa}$ (1.5 bar) nitrogen atmosphere at $-180{ }^{\circ} \mathrm{C}$, and then survive up to $1.0 \times 10^{6} \mathrm{~Pa}(10 \mathrm{bar})$ of $-180{ }^{\circ} \mathrm{C}$ liquid ethane/ methane. The antenna greatly increases the drag on the sub when submerged but that can be offset using the power not needed for communications ( $250 \mathrm{~W})$ for the propeller-based propulsion units (propulsors).

Propulsion using bladed propellers, or propulsors is similar to terrestrial submarines. Four $\sim 100 \mathrm{~W}$ motors attached to booms provide propulsion and maneuvering while below the surface (Figure 6). This multiple thruster design was chosen for several reasons:

- Redundancy to accommodate a motor failure

- Eliminate the need for actuator/fins

- Allow for maneuvering the vehicle at low speeds above and below the surface, and

- Provide easy access to the rear of the hull to load the Stirling Radioisotope Generators on the launch pad due to safety and security requirements.

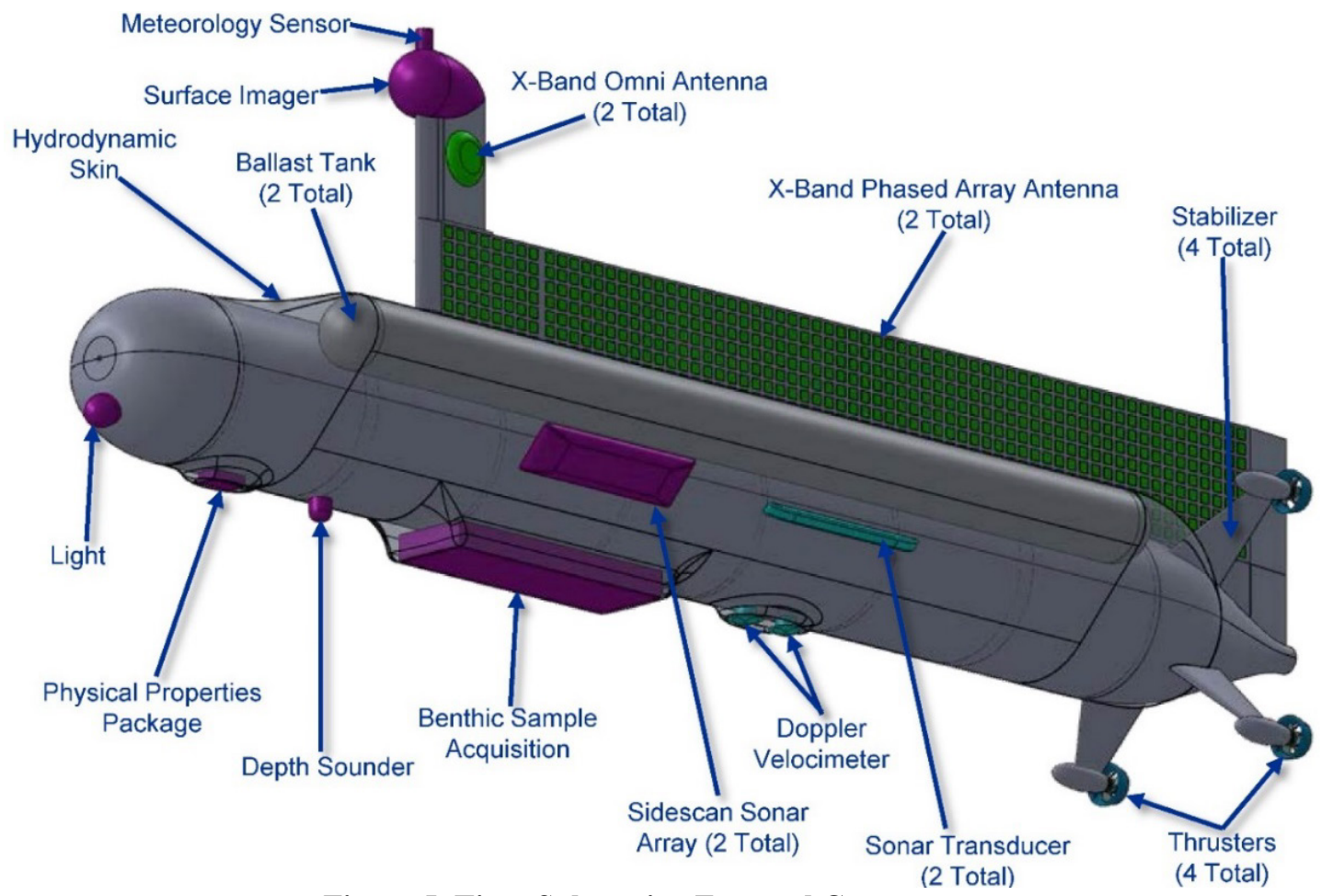

Figure 5. Titan Submarine External Components.

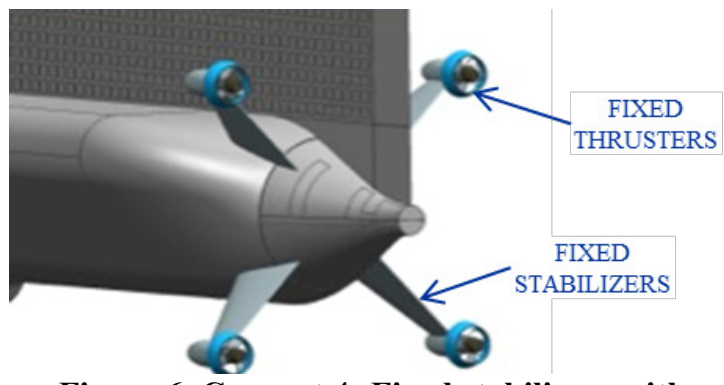

Figure 6. Concept 4: Fixed stabilizers with tip mounted thrusters in $\mathrm{X}$-stern configuration. 


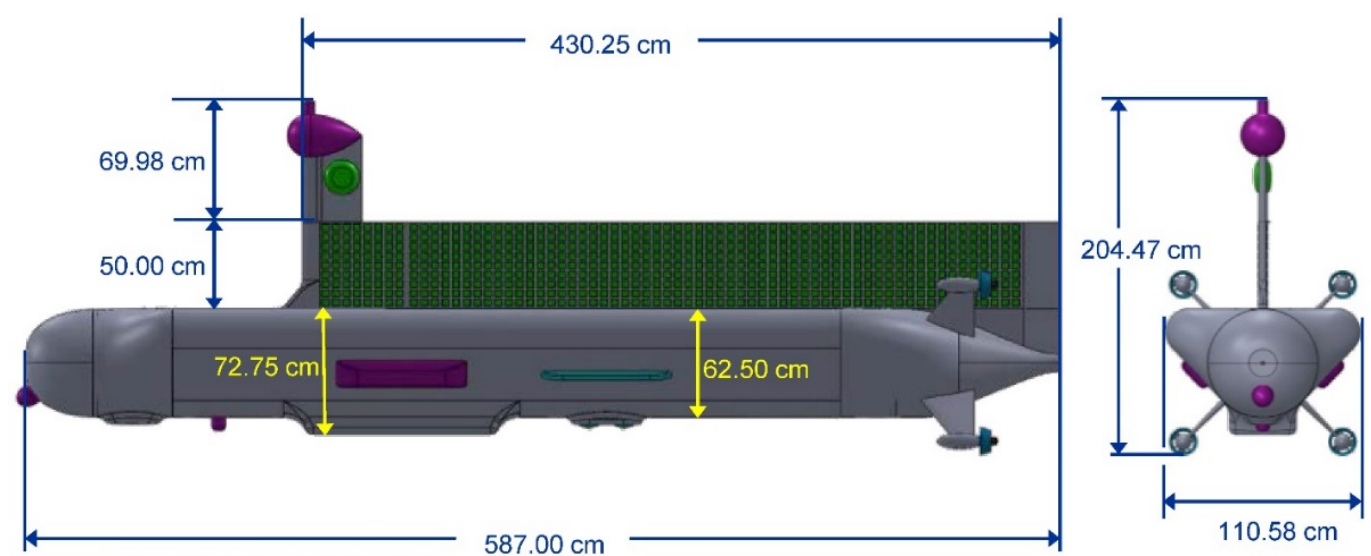

Figure 7. Overall deployed dimensions of the Titan Submarine.

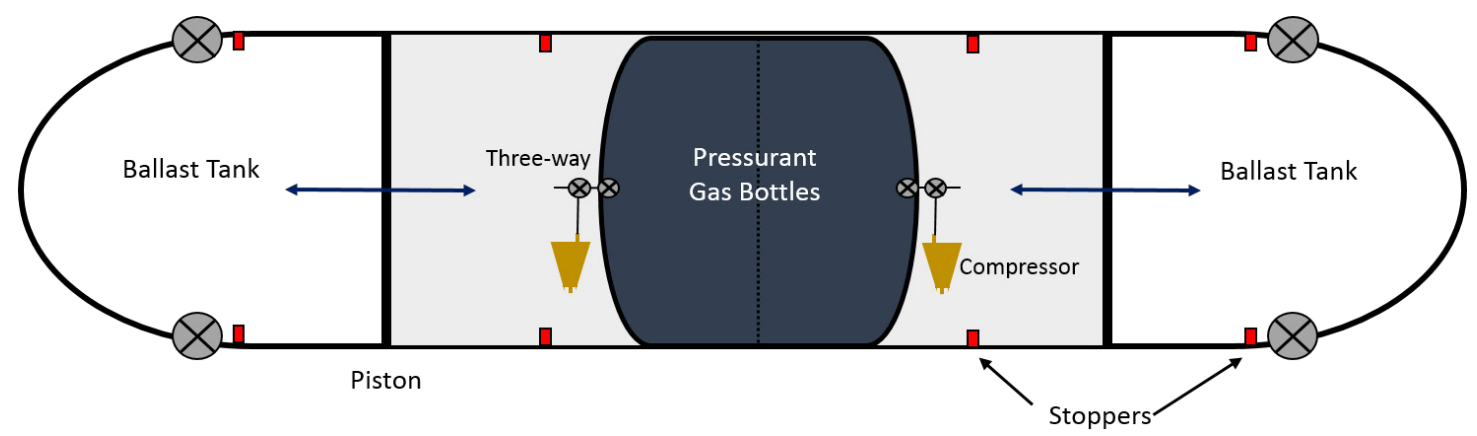

Figure 8. Ballast Tank Concept

Since drag is lessened on the surface only two motors are used during surface cruise. Cavitation on the propellers due to boiling of the ethane is probably not a concern.

The biggest challenge for submarine operations was submerging. Terrestrial submarines use various techniques from diving planes and thrust to ballast tanks filled and then 'blown' using compressed atmospheric gases to venture beneath the waves then return to the surface. While use of thrusters and 'wings' to go beneath Kraken is possible, science required neutral buoyancy hovering for submerged imaging and sampling. Using thrusters to offset buoyancy at depth to hover would require about four times the power from the Stirling Radioisotope Generators than is available. Use of a compressed gas ballast system (Figure 8) using Titan's primarily nitrogen atmosphere was found to be infeasible due both to the fact that ethane (and especially methane) can quickly absorb the nitrogen and the nitrogen at $-180{ }^{\circ} \mathrm{C}$ collapses to a liquid below 4 bar which would limit depths to $\sim 200 \mathrm{~m}$. As such, a boundary between the ballast gas and the ethane as well as use of a gas with a lower liquid point was used. The final system uses cylindrical ballast tanks with either free floating pistons or bladders pressurized by neon brought from Earth and reclaimed after each dive by a compressor during the $16 \mathrm{hr}$ of surface operations (Figure 8). The use of the boundary 'piston' meant that the ballast tanks could not be conformal with the pressure hull, following its contours like those of a terrestrial submarine. The positions of the ballast tanks were offset upward to raise the center of buoyancy. The pressure hull and the buoyancy tanks were overwrapped with a composite to create a pseudo $\mathrm{v}$-shaped hull shape to provide better surface stability for antenna pointing and more efficient surface mobility when power was limited (Figure 9). 


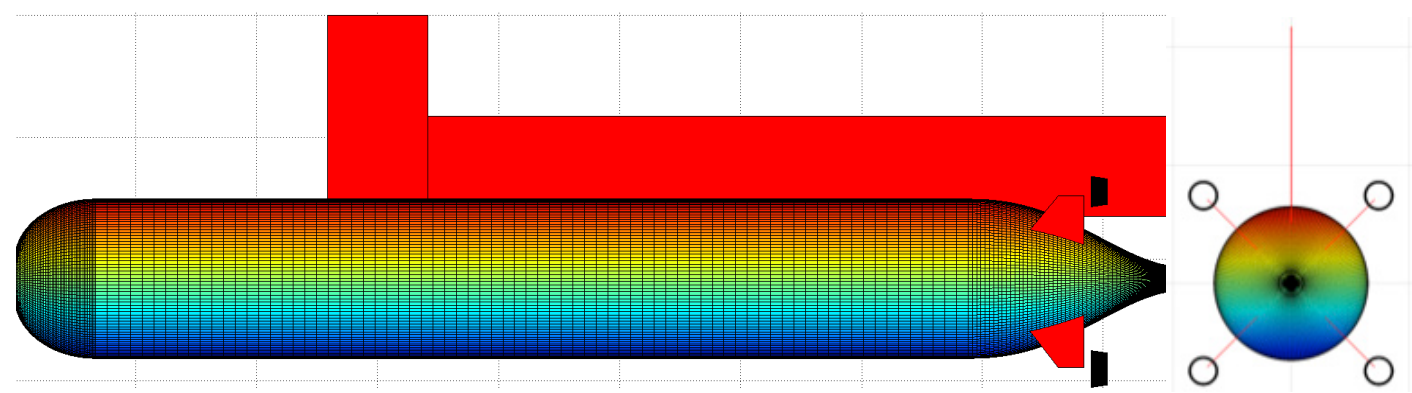

Figure 9. Vehicle geometry analyzed in stability code.

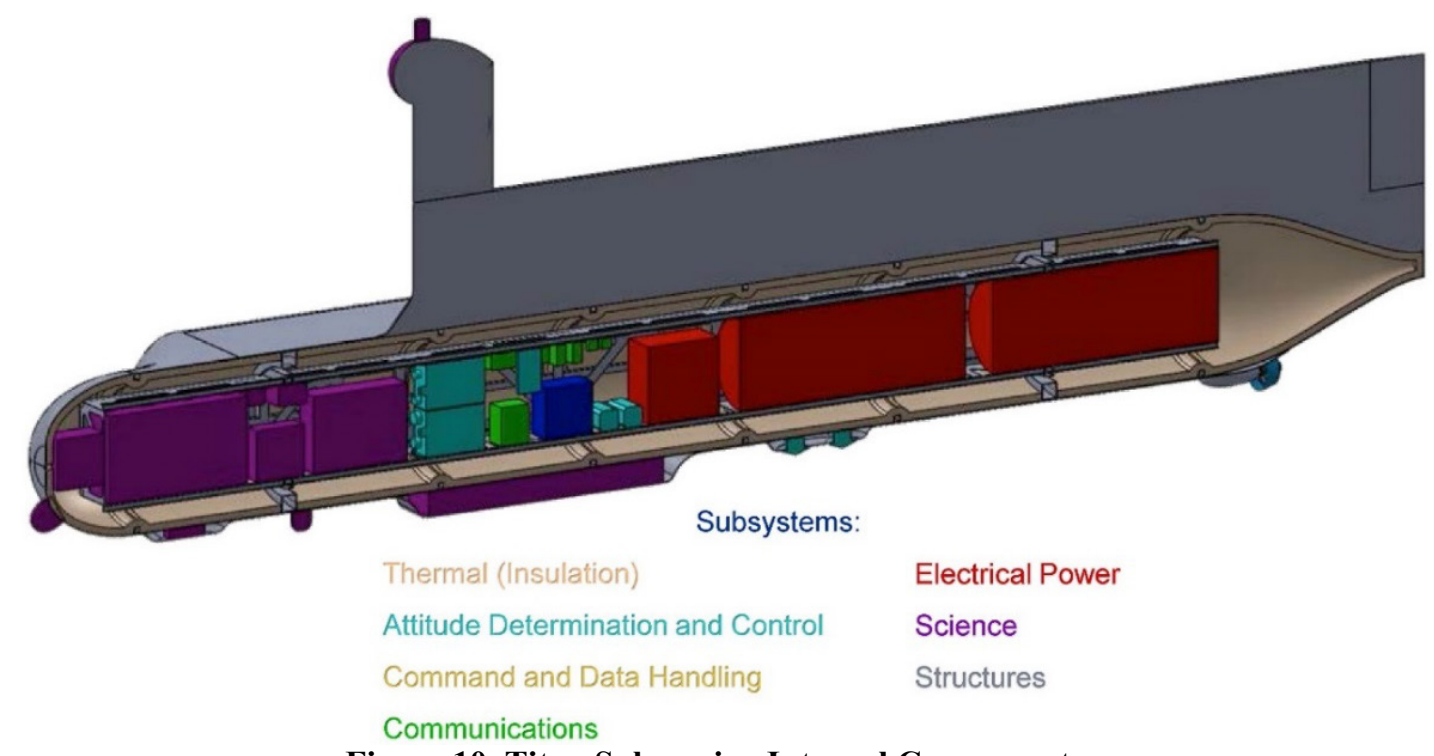

Figure 10. Titan Submarine Internal Components.

The final design shown in Figure 10 has a mass of approximately $1,386 \mathrm{~kg}(3,056 \mathrm{lbm})$ mass. The sub is $6 \mathrm{~m}$

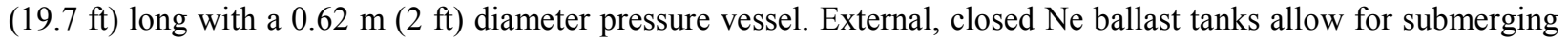
and hovering at depths as deep as $1,000 \mathrm{~m}(3,281 \mathrm{ft})$ and pressures up to $1 \mathrm{MPa}(10 \mathrm{bar}$.)

The major systems of the submarine are summarized below:

- Power: Two $430 \mathrm{~W}$ end of life Stirling Radioisotope Generators (total power $860 \mathrm{~W}$ ), loading through rear hatch of aerovehicle/submarine

- Propulsion: Four $100 \mathrm{~W}$ motors on booms to provide up to $1.6 \mathrm{~m} / \mathrm{s}(5.2 \mathrm{ft} / \mathrm{s})$ submerged and $0.9 \mathrm{~m} / \mathrm{s}(3 \mathrm{ft} / \mathrm{s})$ surface speeds, as well as differential steering

- Avionics: X-Band communications DTE ( $\sim 800$ bps during $16 \mathrm{hr}$ Deep Space Network passes each day surfaced) using $250 \mathrm{~W}$ DC, 4- by $0.5-\mathrm{m}$ (13.1- by 1.6-ft) phased array dorsal antenna; Dual X-band omni antennas; Autonomous Command and Data Handling for $16 \mathrm{hr} / \mathrm{d}$ surface and $8 \mathrm{hr} / \mathrm{d}$ submerged exploration; Navigation using Inertial Measurement Unit, Sun direction, Earth tracking, liquid velocity Doppler, sonar scanning

- Thermal: Most systems internal warmed by Stirling Radioisotope Generators waste heat; $3 \mathrm{~cm}$ (1.1 in.) thick aerogel insulation; $300 \mathrm{~W} / \mathrm{m}^{2}$ heat loss thru outer skin; external systems -some science, communications antennas, propulsion, ballast systems must be cryo-capable $\left(-178^{\circ} \mathrm{C}\right)$

- Mechanical: Pressure vessel capable of withstanding an external pressure of $1 \times 10^{6} \mathrm{~Pa}$ (10 bar); titanium skin and ring stiffeners; internal truss to carry equipment through launch; composite hydrodynamic fairing; dorsal sail to hold phased array antenna and surface science.

1. Titan Submarine Architecture Summary

The MEL shown in Table 5 captures the bottoms-up estimation of current best estimate and growth percentage of the Titan Submarine that the subsystem designers calculated for each line subsystem. In order to meet the total required system mass growth of 30 percent, an allocation is necessary for growth on basic dry mass at the system 
level, in addition to the growth calculated on each individual subsystem. This additional system-level mass is counted as part of the inert mass to be flown. The additional system-level growth mass also impacts the total ballasting required on the sub to assure buoyancy control.

Table 5. Titan Submarine Architecture Summary

\begin{tabular}{|c|c|c|c|c|c|}
\hline \multicolumn{6}{|c|}{ Spacecraft MEL Rack-Up (Mass)_Case 1 Titan Sub CD-2014-114 } \\
\hline WBS & Main subsystems & $\begin{array}{c}\text { Basic mass, } \\
\mathrm{kg}\end{array}$ & $\begin{array}{l}\text { Growth, } \\
\mathrm{kg}\end{array}$ & $\begin{array}{c}\text { Predicted mass, } \\
\mathrm{kg}\end{array}$ & $\begin{array}{c}\text { Aggregate growth, } \\
\%\end{array}$ \\
\hline 06 & Titan Sub Spacecraft & 901.8 & 183.1 & 1085.0 & --- \\
\hline 06.1 & Titan Sub & 901.8 & 183.1 & 1085.0 & 20 \\
\hline 06.1 .1 & Science Payload & 91.0 & 27.3 & 118.3 & 30 \\
\hline 06.1 .2 & Attitude, Determination \& Control & 32.9 & 5.9 & 38.8 & 18 \\
\hline 06.1 .3 & Command and Data Handling & 44.0 & 13.2 & 57.2 & 30 \\
\hline 06.1 .4 & Communications and Tracking & 26.3 & 4.2 & 30.5 & 16 \\
\hline 06.1 .5 & Electrical Power Subsystem & 146.0 & 29.2 & 175.2 & 20 \\
\hline 06.1 .6 & Thermal Control (Non-Propellant) & 95.3 & 17.2 & 112.5 & 18 \\
\hline 06.1 .7 & Propulsion & 20.6 & 5.9 & 26.5 & 29 \\
\hline 06.1 .8 & Propellant & 0.0 & ----- & 0.0 & TBD \\
\hline 06.1 .9 & Not Used & 0.0 & 0.0 & 0.0 & TBD \\
\hline 06.1 .10 & Not Used & 0.0 & & 0.0 & TBD \\
\hline 06.1 .11 & Structures and Mechanisms & 445.7 & 80.2 & 525.9 & 18 \\
\hline & Element 1 consumables (if used) & 0.0 & ------ & 0.0 & --- \\
\hline & Estimated Spacecraft dry mass (no prop, consumables) & 901.8 & 183.1 & 1085.0 & 20 \\
\hline & Estimated Spacecraft wet mass & 901.8 & 183.1 & 1085.0 & -- \\
\hline \multicolumn{5}{|c|}{ System level growth calculations titan sub } & Total growth \\
\hline & Dry mass desired system level growth & 901.8 & 270.5 & 1172.4 & 30 \\
\hline & Additional Growth (carried at system level) & ------ & 87.4 & ------- & 10 \\
\hline & Total wet mass with growth & 901.8 & 270.5 & 1172.4 & \\
\hline \multicolumn{6}{|c|}{ Hydrostatic balance } \\
\hline & Foam in voids between pressure hull and ballast & 34.0 & & & \\
\hline & Additional lead ballast & 180.0 & & & \\
\hline \multicolumn{4}{|c|}{ Total wet mass with growth and balance } & 1386.4 & \\
\hline
\end{tabular}

\section{2. $\quad$ Power Equipment List (PEL)}

To model the power systems in this Titan Submarine design study, 10 modes of operation were defined for the study. These modes were defined based on the mission profile and they identify which items and subsystems of the sub are operating, and which items are dormant and require no power, at any time throughout the mission. The definitions of these modes are shown in Table 6.

Table 7(a) and (b) show the assumptions about the power requirements across all modes of operation. The power requirements from the bottoms-up analysis on the titan sub shown in those tables are used by the power system designers to size the power system components and by the Thermal Control System lead to manage the waste heat from these components.

Table 6. Power Modes for the Titan Submarine Study

\begin{tabular}{|l|l|c|}
\hline \multicolumn{1}{|c|}{ Power Mode Names } & \multicolumn{1}{|c|}{ Description } & Duration \\
\hline Launch & Ascent through Earth departure & $60 \mathrm{~min}$ \\
\hline Interplanetary Cruise & Keep-alive power during hibernation; occasional wake up and c/o & $7 \mathrm{yr}$ \\
\hline Titan entry, descent and landing & Entry, descent and splashdown & $2 \mathrm{hr}$ \\
\hline Sub Activation and Checkout & Commissioning & $1 \mathrm{wk}$ \\
\hline Dive/Surface & & $100 \mathrm{mi}$ \\
\hline SubmergedCruise & Including science and h/k communications (low data rate) & $8 \mathrm{hr}$ \\
\hline SurfaceCruise & Including science and communications (high data rate) & $16 \mathrm{hr}$ \\
\hline Stationary Submerged Operations & Including science and h/k communications (low data rate) & $8 \mathrm{hr}$ \\
\hline StationarySurfaceOperations & Including science and communications (high data rate) & $16 \mathrm{hr}$ \\
\hline End of mission disposal & & \\
\hline
\end{tabular}


Table 7. PEL for the Titan Submarine

(a) Modes 1 to 5

\begin{tabular}{|c|c|c|c|c|c|c|}
\hline \multirow[t]{3}{*}{$\begin{array}{c}\text { WBS } \\
\text { number }\end{array}$} & $\begin{array}{c}\text { Description } \\
\text { Case } 1 \text { Titan Sub CD-2014-114 }\end{array}$ & $\begin{array}{c}\text { Power mode } 1 \text {, } \\
\text { W }\end{array}$ & $\begin{array}{c}\text { Power mode } 2 \text {, } \\
\text { W }\end{array}$ & $\begin{array}{c}\text { Power mode } 3, \\
\text { W }\end{array}$ & $\begin{array}{c}\text { Power mode } 4 \text {, } \\
\text { W }\end{array}$ & $\begin{array}{c}\text { Power mode } 5 \text {, } \\
\text { W }\end{array}$ \\
\hline & Power mode name & Launch & $\begin{array}{l}\text { Interplanetary } \\
\text { Cruise }\end{array}$ & $\begin{array}{c}\text { Titan entry, } \\
\text { descent and } \\
\text { landing }\end{array}$ & $\begin{array}{l}\text { Sub Activation } \\
\text { and Checkout }\end{array}$ & Dive/Surface \\
\hline & Power mode duration & $60 \mathrm{~min}$ & $7 \mathrm{yr}$ & $2 \mathrm{hr}$ & $1 \mathrm{wk}$ & $100 \mathrm{~min}$ \\
\hline 06 & Titan Sub Spacecraft & 60.0 & 70.0 & 90.0 & 648.0 & 635.0 \\
\hline 06.1 & Titan Sub & 60.0 & 70.0 & 90.0 & 648.0 & 635.0 \\
\hline 06.1 .1 & Science Payload & 0.0 & 0.0 & 0.0 & 55.0 & 53.0 \\
\hline 06.1 .2 & Attitude, Determination \& Control & 0.0 & 0.0 & 0.0 & 63.0 & 52.0 \\
\hline 06.1 .3 & Command and Data Handling & 60.0 & 60.0 & 60.0 & 60.0 & 60.0 \\
\hline 06.1 .4 & Communications and Tracking & 0.0 & 10.0 & 30.0 & 30.0 & 30.0 \\
\hline 06.1 .5 & Electrical Power Subsystem & 0.0 & 0.0 & 0.0 & 0.0 & 0.0 \\
\hline 06.1 .6 & Thermal Control (Non-Propellant) & 0.0 & 0.0 & 0.0 & 0.0 & 0.0 \\
\hline 06.1 .7 & Propulsion & 0.0 & 0.0 & 0.0 & 440.0 & 440.0 \\
\hline 06.1 .8 & Propellant & 0.0 & 0.0 & 0.0 & 0.0 & 0.0 \\
\hline 06.1 .9 & Not Used & 0.0 & 0.0 & 0.0 & 0.0 & 0.0 \\
\hline 06.1 .10 & Not Used & 0.0 & 0.0 & 0.0 & 0.0 & 0.0 \\
\hline 06.1 .11 & Structures and Mechanisms & 0.0 & 0.0 & 0.0 & 0.0 & 0.0 \\
\hline 06.2 & Entry System & 0.0 & 0.0 & 0.0 & 0.0 & 0.0 \\
\hline 06.3 & Cruise Stage & 0.0 & 0.0 & 0.0 & 0.0 & 0.0 \\
\hline & Bus Power, System Total & 60.0 & 70.0 & 90.0 & 648.0 & 635.0 \\
\hline & $30 \%$ growth & 18.0 & 21.0 & 27.0 & 194.4 & 190.5 \\
\hline & Total Bus Power Requirement & 78.0 & 91.0 & 117.0 & 842.4 & 825.5 \\
\hline
\end{tabular}

Table 7. PEL for the Titan Submarine

(b) Modes 6 to 10

\begin{tabular}{|c|c|c|c|c|c|c|}
\hline \multirow[t]{3}{*}{$\begin{array}{l}\text { WBS } \\
\text { number }\end{array}$} & $\begin{array}{c}\text { Description } \\
\text { Case } 1 \text { Titan Sub CD-2014-114 }\end{array}$ & $\begin{array}{l}\text { Power mode } 6 \text {, } \\
\text { W }\end{array}$ & $\begin{array}{l}\text { Power mode } 7 \text {, } \\
\text { W }\end{array}$ & $\begin{array}{c}\text { Power mode } 8 \text {, } \\
\text { W }\end{array}$ & $\begin{array}{l}\text { Power mode } 9 \text {, } \\
\text { W }\end{array}$ & $\begin{array}{l}\text { Power mode } 10 \text {, } \\
\text { W }\end{array}$ \\
\hline & Power mode name & $\begin{array}{l}\text { Submerged } \\
\text { Cruise }\end{array}$ & $\begin{array}{l}\text { Surface } \\
\text { Cruise }\end{array}$ & $\begin{array}{c}\text { Stationary } \\
\text { Submerged } \\
\text { Operations }\end{array}$ & $\begin{array}{c}\text { Stationary } \\
\text { Surface } \\
\text { Operations }\end{array}$ & $\begin{array}{c}\text { End of mission } \\
\text { Disposal }\end{array}$ \\
\hline & Power mode duration & $8 \mathrm{hr}$ & $16 \mathrm{hr}$ & $8 \mathrm{hr}$ & $16 \mathrm{hr}$ & 0.0 \\
\hline 06 & Titan Sub Spacecraft & 645.0 & 573.5 & 207.0 & 411.0 & 128.0 \\
\hline 06.1 & Titan Sub & 645.0 & 573.5 & 207.0 & 411.0 & 128.0 \\
\hline 06.1 .1 & Science Payload & 53.0 & 43.0 & 55.0 & 23.0 & 0.0 \\
\hline 06.1 .2 & Attitude, Determination \& Control & 62.0 & 53.0 & 62.0 & 53.0 & 53.0 \\
\hline 06.1 .3 & Command and Data Handling & 60.0 & 60.0 & 60.0 & 60.0 & 60.0 \\
\hline 06.1 .4 & Communications and Tracking & 30.0 & 280.0 & 30.0 & 275.0 & 15.0 \\
\hline 06.1 .5 & Electrical Power Subsystem & 0.0 & 0.0 & 0.0 & 0.0 & 0.0 \\
\hline 06.1 .6 & Thermal Control (Non-Propellant) & 0.0 & 37.5 & 0.0 & 0.0 & 0.0 \\
\hline 06.1 .7 & Propulsion & 440.0 & 100.0 & 0.0 & 0.0 & 0.0 \\
\hline 06.1 .8 & Propellant & 0.0 & 0.0 & 0.0 & 0.0 & 0.0 \\
\hline 06.1 .9 & Not Used & 0.0 & 0.0 & 0.0 & 0.0 & 0.0 \\
\hline 06.1 .10 & Not Used & 0.0 & 0.0 & 0.0 & 0.0 & 0.0 \\
\hline 06.1 .11 & Structures and Mechanisms & 0.0 & 0.0 & 0.0 & 0.0 & 0.0 \\
\hline 06.2 & Entry System & 0.0 & 0.0 & 0.0 & 0.0 & 0.0 \\
\hline 06.3 & Cruise Stage & 0.0 & 0.0 & 0.0 & 0.0 & 0.0 \\
\hline & Bus Power, System Total & 645.0 & 573.5 & 207.0 & 411.0 & 128.0 \\
\hline & $30 \%$ growth & 193.5 & 172.0 & 62.1 & 123.3 & 38.4 \\
\hline & Total Bus Power Requirement & 838.5 & 745.5 & 269.1 & 534.3 & 166.4 \\
\hline
\end{tabular}




\section{Cost Estimates}

The cost estimates for the submarine assuming components are at technology readiness level 6 and above ${ }^{8}$ is around $\$ 700 \mathrm{M}$ (fiscal year 14). The technology development, lifting body and launch service would easily take this concept into the flagship cost level.

\section{Phase II Plans}

In July the Titan Submarine effort was awarded a NIAC phase II award for 2 years and \$500K. The Phase II efforts will center around retiring the risks identified in phase I, refining science goals and instruments and exploring alternate submerged approaches through additional COMPASS runs.

The major risks found in the Phase I conceptual design center around vehicle operations in a liquid hydrocarbon sea. Basic physics questions of operating in this cryogen need to be answered. Cryogenic experts at GRC will develop models to explore mixtures and pressures of cryogens and gases and how they would react with a warm submarine. Results from these models will be used to refine the ballast and propulsion system conceptual designs as well as feed into development of a hydrodynamic fluid models at ARL for evaluating the conceptual design.

Cassini continues to observe both the constituents (remotely) and the depth of the northern Titan Seas. Up-todate data will be gathered and used as inputs for the modeling mentioned above. These data, along with the above analysis results, will be used to refine the science goals, concept of operations, and instrument suite for the Titan Sub. These activities will be led by JHU APL. The Phase II efforts will be strengthened by workshops at selected science and cryogenic conferences that will include scientists, cryogenic engineers (including the liquid natural gas industry) respectively, as well as NASA project planners to review the Titan Sub concept and add direction and experience to the challenges it faces.

The results of all the above efforts will feed into a COMPASS current engineering design run to update the current Titan Sub conceptual design to mature the concept. Launch and delivery options will be explored (in Phase I funds were not sufficient to design more than the Sub itself) on how to deliver this long cylindrical submarine with support from Aero-Entry experts at Georgia Tech. Risks of an exposed phased-array antenna to communicate directly back to Earth will also be explored. A second COMPASS run will develop a Titan Sub that would be delivered as part of an orbiter system. The presence of an orbiter would greatly simplify several aspects of the submarine design, especially delivery and communications.

\section{Benefits of the Titan Sub}

Except for the Phase I Titan Submarine study, report, and numerous papers, no one has explored the feasibility of an extraterrestrial, cryogenic ocean submarine. Even though the Titan Sub is looking only at the Titan seas, the entire concept has many attributes, technologies, and mission solutions that can be applied to other extraterrestrial seas - even those containing water, such as Europa. Guidance, navigation, power, hydrodynamics, communications, science, and delivery all have common solutions regardless of which extraterrestrial sea.

The Titan Sub Phase II study will have several wider benefits: The results of Phase I have already engaged the public with a multitude of news stories, both on the Web and local news programs, with half a million hits on its concept video. ${ }^{9}$ Most notable is the BBC article "Is Titan Submarine the Most Daring Mission Yet?" 10 In addition, the cryogenic Sub's technologies will certainly have impact on the liquefied natural gas community in the form of pumps, seals, and alternative operating environments. Regardless of the eventual launch date of a Titan submarine, there are several immediate scientific and engineering benefits to the Phase II research, including (1) better understanding of the seas of Titan with the cryogenic modeling tasks, (2) solutions on delivery and operation of extraterrestrial submersibles for other moons, and (3) cryogenic concepts for both NASA's cryogenic fluid management research (cryogenic motors, valves seals, pumps, and instrumentation) and the liquefied natural gas community.

The Titan Submarine (Figure 11) has already shown itself to be inspiring to the public and is certainly pioneering the way for extraterrestrial submersible exploration of Titan and other moons. From a scientific standpoint no exploration of Titan would be complete without a submersible, just as excluding exploration of Earth's oceans below the surface would leave us with much less understanding of our own planet. 


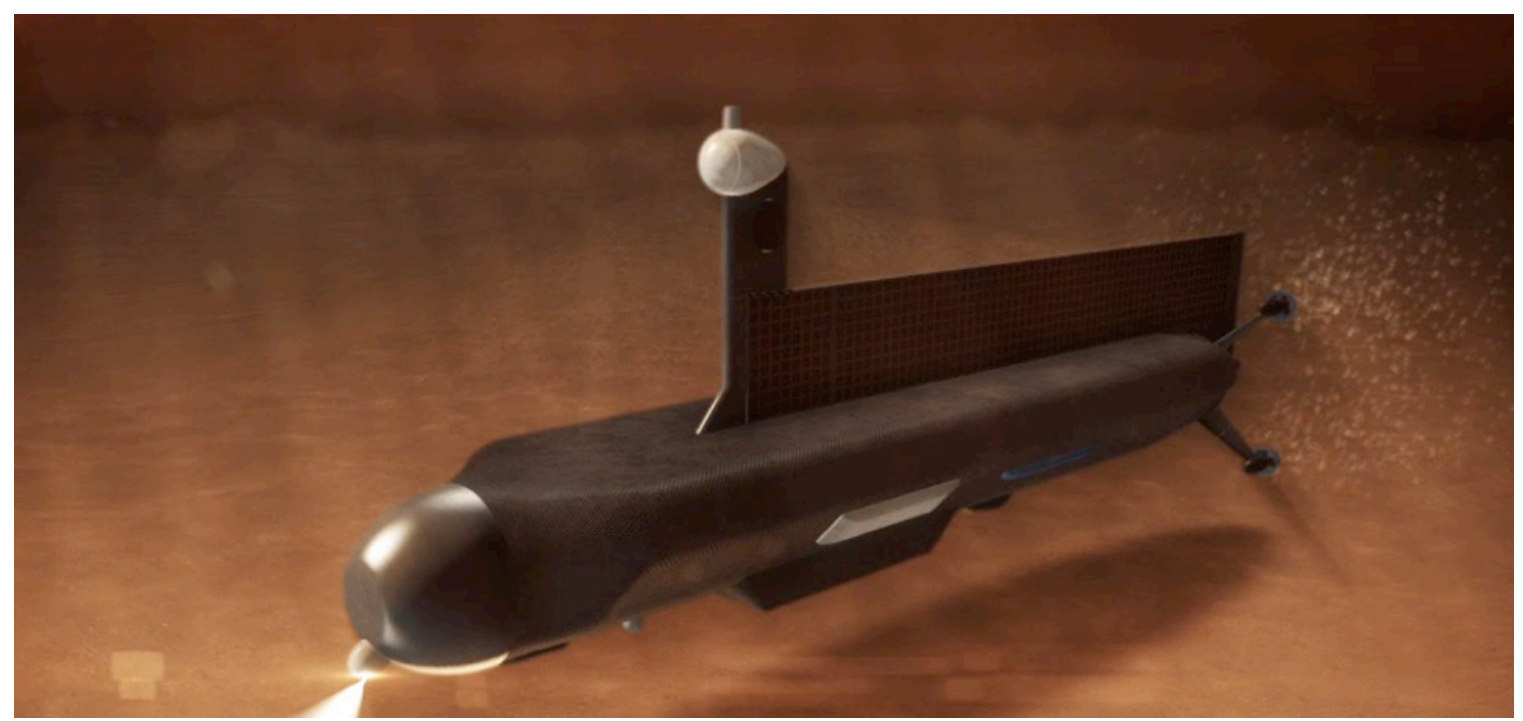

Figure 11. Artist concept of the Titan Submarine.

\section{Acknowledgments}

This work was funded the NASA Innovative Advanced Concepts (NIAC) program as a Phase I Study in 2014. The authors wish the heartily thank the NIAC program Team: Jay Falker, Jason Derleth, Ron Turner, Katherine Reilly, and Barbara Mader for their guidance, patience and insight during this conceptual design study. The investigators also wish to acknowledge with the strongest possible vigor the contributions of the COMPASS team to the Titan Submarine design. Without their creativity, innovation, and perseverance the submarine's design would never have been created: Cryogenics, Jason Hartwig; Hydrodynamics Engineer, Justin Walsh (PSU/ARL); Systems Engineer, Jeff Woytach; Science, Geoff Landis; Navigation, Mike Martini; Mechanical Systems, Amy Stalker; Thermal Control, Anthony Colozza; Power, Paul Schmitz; Command and Data Handling and Software, Hector Dominguez; Communications, Robert Jones; Configuration, Tom Packard; Visualization, Michael Bur; and Cost, Tom Parkey and Elizabeth Turnbull. We also wish to thank Les Balkanyi, Lorie Passe, Lisa Liuzzo, and Eric Mindek for bringing the Titan Submarine to life in word, pictures, and video- the American public, indeed the world, knows of the Titan Submarine because of their work. Finally, a nod to dreamers such as Jules Verne who inspire us to explore new worlds: Mobilis in Glaciali!

\section{References}

${ }^{1}$ Oleson, S. R., Lorenz, R. D., and Paul, M. V., "Phase I Final Report: Titan Submarine,” NASA/TM-2015-218831. http://www.sti.nasa.gov/ [cited 7 August 2015].

${ }^{2}$ Lorenz, R. D., Oleson, S. R., Woytach, J., Jones, R., Colozza, A., Paul Schmitz, Landis, G., Paul, M., and Walsh J., “Titan Submarine : Vehicle Design and Operations Concept for the Exploration of the Hydrocarbon Seas of Saturn's Giant Moon," The 46th Lunar and Planetary Science Conference, Universities Space Research Association (USRA), The Woodlands, Texas, 2015. URL: http://www.hou.usra.edu/meetings/lpsc2015/pdf/1259.pdf [cited 7 August 2015].

${ }^{3}$ Hartwig, J. W., Colozza, A., Lorenz, R. D., Oleson, S., Paul, M., and Walsh, J. "Exploring the Depths of Kraken Mare Power, Thermal Analysis, and Ballast Control for the Saturn Titan Submarine" Cryogenics 2015 (in press).

${ }^{4}$ Hartwig, J.W., Oleson, S., Lorenz, R., Colozza, A., and Schmitz, P. "Thermal Design Concerns for the Saturn Titan Submarine" 2016 American Society of Gravitational and Space Research Conference, Alexandria, Virginia, 2015.

${ }^{5}$ Lorenz, R. D., “A Review of Titan Mission Studies," Journal of the British Interplanetary Society, 62, 162-174, 2009.

${ }^{6}$ Stofan, E., Lorenz,, R. Lunine, J., Bierhaus, E., Clark, B., Mahaffy, P., and Ravine, M., "TiME - The Titan Mare Explorer," IEEE Aerospace Conference, Big Sky, MT, paper no. 2434, 2013.

${ }^{7}$ Leary, J., Jones, C., Lorenz, R., Strain, R. D., and Waite, J. H., "Titan Explorer NASA Flagship Mission Study,” Johns Hopkins University, Applied Physics Laboratory, The Lunar and Planetary Institute, The Outer Planets Assessment Group, January 2008, http://www.lpi.usra.edu/opag/Titan_Explorer_Public Report.pdf [cited 7 August 2015].

${ }^{8}$ NASA TRL Definitions Reference, http://esto.nasa.gov/files/trl definitions.pdf [cited 7 August 2015].

9 Oleson, S. R., "Titan Submarine: Exploring the Depths of Kraken Mare," [online animation] URL: https://www.youtube.com/watch?list=PLiuUQ9asub3RGwm vD0Sb-rzXN?enablejsapi=1\&v=NnKxbdpLP5E [cited 7 August 2015].

${ }^{10}$ Rincon, P. (Science ed.), “Is Titan submarine the most daring space mission yet?" BBC News, Science \& Environment, URL: http://www.bbc.com/news/science-environment-31854559 [cited 7 August 2015]. 